\title{
Selective attention in ambiguous-figure perception: An individual differences analysis
}

\author{
G. ALFRED FORSYTH \\ University of New Hampshire, Durham, New Hampshire 09824 \\ and \\ R. JOHN HUBER \\ Meredith College, Raleigh, North Carolina 27611
}

\begin{abstract}
Ten human vs. nonhuman ambiguous-figure stimuli were presented to a sample of 520 subjects for identification. Using an individual differences analysis, four stimulus factors were identified and homogeneous subgroups of like-perceiving subjects were isolated. Possible cues utilized in judgments of stimulus factors were described. Homogeneous subgroups of subjects were differentially characterized on the basis of age and clinical diagnostic classification. The study illustrates the usefulness of the individual differences approach to the study of ambiguous-figure stimuli.
\end{abstract}

Recent models of perception emphasize an active search for and selection of distinctive dimensions of a stimulus array (Garner, 1974). The majority of selective attention studies have followed Attneave's (1950) suggestion of relating attentional phenomena to specifiable physical dimensions of stimuli (e.g., Forsyth, 1974). Selective attention processes can also operate on the basis of the meaning of the stimuli (e.g., Broadbent, 1970). Whether selective attention is based on physical dimension utilization or on meaning of stimuli, large individual differences have dominated the results (Forsyth \& Shor, 1974; Tucker \& Messick, 1963). The purpose of the present study was to examine selective attention in the perception of ambiguous-figure stimuli with an individual differences approach.

Huber and Forsyth (1972) examined 10 ambiguousfigure stimuli which could be seen as either human or nonhuman. The human aspect of the stimulus consisted of a whole face for five of the stimuli and part of a face for the other five. This a priori grouping of stimuli was partially successful in that the two categories of stimuli produced different results in comparing different age groups and mental health diagnostic categories. However, a re-examination of the relatively large error variability within some age and diagnostic groups led to a concern that the a priori grouping of stimuli may not have been fully appropriate. Our hope was that the individual differences paradigm (Tucker \& Messick, 1963; Forsyth, Note 1) would be useful in our study of ambiguous-figure perception. Specifically, we were interested in the factor analytic subgrouping of stimuli as a first step in searching for the relevant physical or meaningfulness dimensions of these ambiguous figures.

Figure construction, analysis of data, and manuscript preparation were supported by the Research Office of the University of New Hampshire.
Second, we were interested in searching for individual differences variables which differentially characterize homogenous subgroups of like-perceiving subjects. This study represents a re-analysis of a portion of the data obtained by Huber and Forsyth (1972).

\section{METHOD}

The 520 subjects consisted of 50 first graders, 50 third graders, 50 fifth graders, 50 seventh graders, 50 ninth graders, 50 eleventh graders, 100 University of New Hampshire students, and 120 institutionalized patients from New Hampshire State Hospital. Public school students were all from the Portsmouth, New Hampshire city schools.

The 10 ambiguous figures used in this study are shown in Figure 1. The stimuli were either modifications of previously described stimuli (e.g., vase-faces by Rubin, 1915; rabbit-pirate by Leeper, 1935; dog-chef by Wallach \& Austin, 1954; and ratman by Bugelski \& Alampay, 1961) or newly created human vs. nonhuman ambiguous figures. Minor physical alterations of each stimulus were made in order to achieve human responses from approximately $50 \%$ of a college freshman sample.

Each subject was individually shown each of the 10 stimuli for $1 \mathrm{sec}$ per stimulus. The $.457 \times .660 \mathrm{~m}$ display of each stimulus appeared on a screen $2.438 \mathrm{~m}$ in front of the subject. Subjects were told to describe what they saw in each picture. Each response was scored as "human" when the correct human aspect of the stimulus was described. Other responses were scored as "nonhuman." The full procedure is described by Huber and Forsyth (1972).

\section{RESULTS}

The analysis of the date involved: (1) a principle components factor analysis of the human vs. nonhuman scaling data to obtain a matrix with loadings on stimuli and a matrix of factor scores on subjects; (2) forming subgroups of like-perceiving subjects based on the euclidean distances of each subject's factor scores from those of each other subject; (3) pooling the data for each 


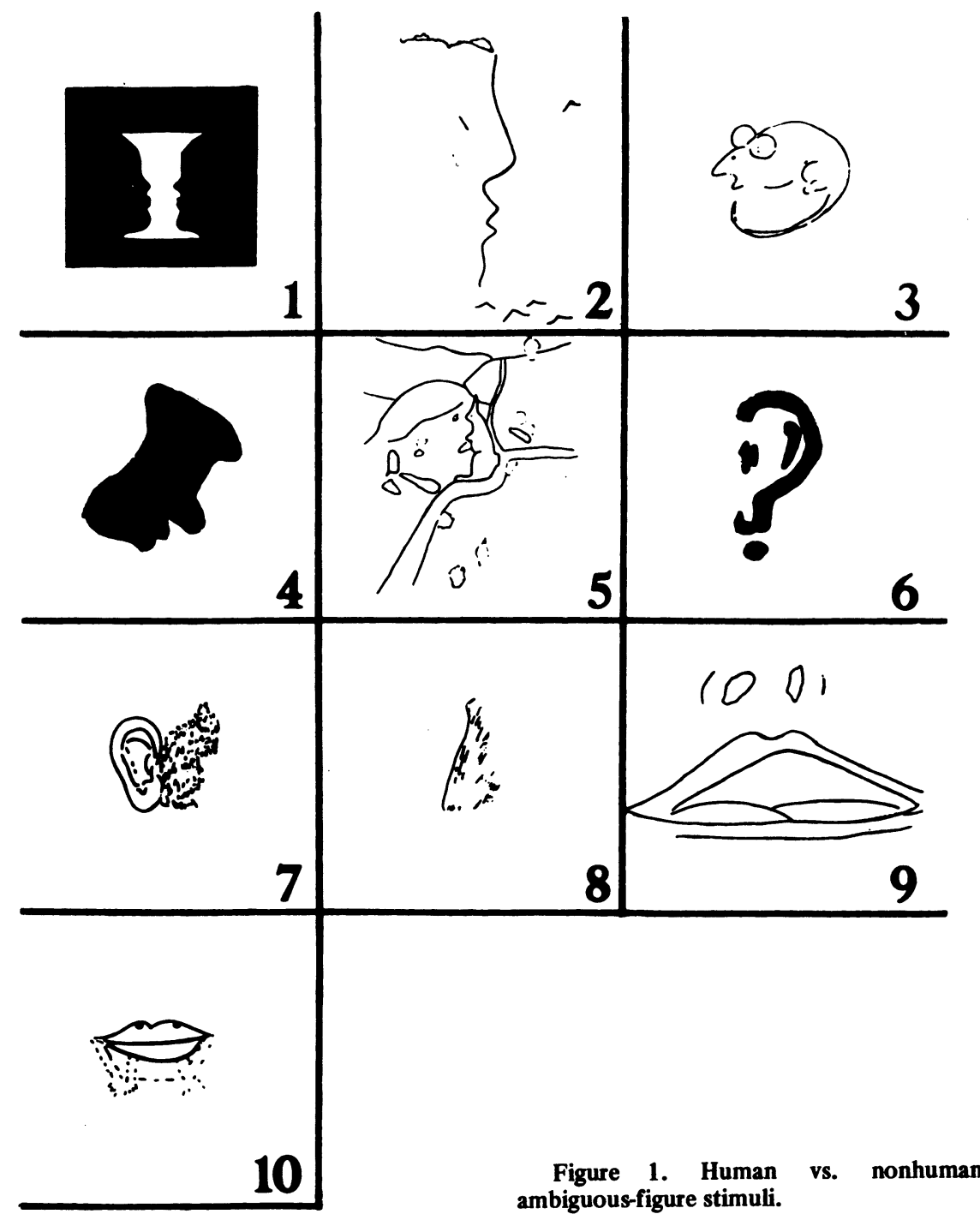

homogeneous subgroup on each stimulus factor to differentially characterize the subgroups on the basis of each stimulus factor; and (4) searching for individual differences classifications which differentially characterize the subgroups.

The principle components factor analysis of the data, using a criterion of eigenvalues greater than unity, resulted in four stimulus factors accounting for $21 \%$, $19 \%, 16 \%$, and $15 \%$ of the variability, respectively.

Table 1 presents the mean stimulus factor loadings for the stimuli comprising each factor. While no stimulus factor consisted of both wholeface and part-face stimuli, the factor analysis clearly indicated two groupings of stimuli within both the whole-face and the part-face stimuli. Factor 2 stimuli (Stimuli 2, 3, and 5 in Figure 1) consisted of side profiles of faces with some details such as eyes providing human cues. Factor 3 stimuli (Stimuli 1 and 4 in Figure 1) were black silhouettes of hüman faces with a white background. Factor 1 stimuli (Stimuli 7, 8, and 10 in Figure 1) consisted of face parts with sketchy or dotted lines providing the nonhuman cues, while the Factor 4 part-face stimuli (Stimuli 6 and 9 in
Figure 1) had no such secondary lines differentiating the human and nonhuman aspects.

An H-group euclidean distance analysis (Ward, 1963) on subject factor scores formed homogeneous subgroups of subjects having similar profiles of perceptual judgments. The factor scores are $\mathrm{Z}$ scores describing the individual's performance on a given stimulus factor. While several categorizable subgroups resulted from this analysis, four pairs of subgroups were of special interest in their relationship to the stimulus factors and to subject classification. Specifically, for each stimulus factor one subgroup of subjects selectively made human

Table 1

Mean Stimulus Factor Loadings for Stimuli Comprising Each Rotated Factor

\begin{tabular}{ccccc}
\hline $\begin{array}{c}\text { Stimulus } \\
\text { Groups }\end{array}$ & 1 & \multicolumn{4}{c}{ Rotated Factor } \\
\hline 1 & .755 & .001 & 3 & 4 \\
\hline 2 & .056 & .773 & .036 & .019 \\
3 & .068 & .070 & .784 & -.001 \\
4 & .094 & .092 & -.176 & -.048 \\
\end{tabular}


Table 2

Number of Subjects in Each Homogeneous Subgroup From Each of Five Subject Categories

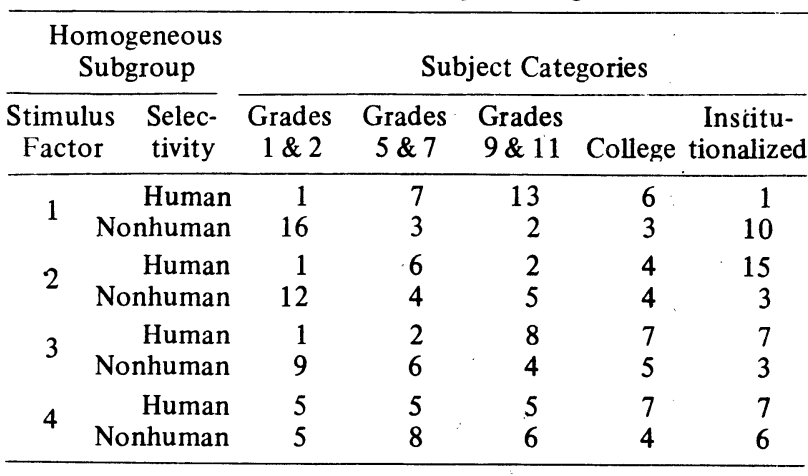

responses and another selectively made nonhuman responses to the stimuli comprising that factor. Table 2 presents a summary of the categories of subjects comprising each of these eight subgroups. Chi square analyses of the Table 2 data indicate different distributions of human and nonhuman responders across the subject categories on the first three stimulus factors. Chi square values ( $4 \mathrm{df})$ for Stimulus Factors 1, 2, and 3 were $30.97(\mathrm{p}<.01), 19.00(\mathrm{p}<.01)$ and $11.69(\mathrm{p}<$ $.02)$, respectively. The very young and the institutionalized had a disproportionately large number of nonhuman responders on Factor 1 stimuli. On Factor 2 stimuli the very young again had a disproportionately large number of nonhuman responders, but a large proportion of institutionalized subjects selectively made human responses to these stimuli, Factor 3 stimuli resulted in a disproportionately large number of nonhuman responders from Grades 1, 3, 5, and 7. The distribution of human and nonhuman responders to these Factor 3 stimuli was almost identical for institutionalized, college, and Grades 9 and 11 categories. No evidence obtained for differential selective responding to the Factor 4 stimuli for the five subject categories (chi square $=1.68, \mathrm{p}>.20$ ). There was some suggestion that selective human vs. nonhuman responding to Factor 4 stimuli may be different for different categories of institutionalized subjects. Specifically, the numbers of humans vs. nonhuman responders to Factor 4 stimuli were 1 vs. 2 for neurotics, 1 vs. 4 for schizophrenics, and 5 vs. 0 for sociopaths.

\section{DISCUSSION}

The individual differences analysis of this data indicates that it is a useful paradigm in the study of ambiguous-figure perception. The 10 ambiguous-figure stimuli were organized into four distinct groupings. There were specific features common to the stimuli comprising the stimulus factors. For example, the black silhouette of the side view of a person's face is common to Factor 3 stimuli; the line drawing of the side profile of a person's face with details of eyes, nose, and mouth cues is common to Factor 2 stimuli; and focal attention to dotted or secondary lines is necessary to perceive the nonhuman aspect of Factor 1 stimuli.

Few materials are available for use as ambiguous-figure stimuli. Additional stimuli for future studies must include more human vs. nonhuman ambiguous figures, but also all other stimuli which can be seen in two or more different ways. The loadings of new stimuli on the stimulus factors will be helpful in refining the physical determinants of response to each stimulus factor. For example, Boring's (1930) "wife and motherin-law" figure would be useful in determining the role of the mouth in Factor 2 stimuli. If the mouth is critical, the "motherin-law" would be more likely seen by those making human responses to the mountain-mouth, rat-man, and rabbit-pirate stimuli. Similarly, an examination of the tree-duck stimulus (Eagle, Wolitzky, \& Klein, 1966) to Factor 3 stimuli would be useful in determining the role of face profile features vs. attention to black silhouettes as figures.

The results of the present analysis indicate that the a priori grouping of stimuli by Huber and Forsyth (1972) was only partially appropriate. No stimulus factor in the present analysis combined a whole-face with a part-face stimulus. However, the separation of stimuli into different factors within both the whole-face and part-face stimuli emphasizes the importance of the individual differences approach to forming stimulus factors and characterizing subgroups of like-perceiving subjects.

\section{REFERENCE NOTE}

1. Forsyth, G. A. Individual differences in information processing: $A$ comparison of paradigms. Paper presented at the meeting of the Canadian Psychological Association, Victoria, British Columbia, June 1973.

\section{REFERENCES}

Attneave, F. Dimensions of similarity. American Journal of Psychology, 1950, 63, 516-556.

Boring. E. G. A new ambiguous figure. American Journal of Psychology, 1930, 42, 444-445.

Broadbent, D. E. Stimulus set and response set: Two kinds of selective attention. In D. I. Mostofsky (Ed.), Attention: Contemporary theory and analysis. New York: AppletonCentury-Crofts, 1970. Pp. 51-60.

Bugelski, B. R., \& Alampay, D. A. The role of frequency in developing perceptual sets. Canadian Journal of Psychology, 1961, 15, 205-211.

EAGLE, M., Wolitzky, D. L., \& KLEIN, G. S. Imagery: Effect of a concealed figure in a stimulus. Science, 1966, 151, 837-839.

ForSYTH, G. A. Effects of training in selective attention on perceptual discrimination. Perceptual and Motor Skills, 1974, 38, 935-944.

Forsyth, G. A., \& Shor, R. E. An individual differences analysis of interdimensional additivity in multidimensional scaling. Perception \& Psychophysics, 1974, 15, 563-567.

GARNER, W. R. Attention: The processing of multiple sources of information. In E. C. Carterette \& M. P. Friedman (Eds.), Handbook of perception, Vol. 2. New York: Academic Press, 1974. Pp. 23-59.

Huber, R. J.,\& Forsyth, G. A. Selective attention and social interest. Journal of Individual Psychology, 1972, 28, 51:59.

LEEPER, R. W. A study of a neglected portion of the field of learning: The development of sensory organization. Journal of Genetic Psychology, 1935, 46, 41-75.

RubIN, E. Synsoplevede figurer. Copenhagen: Glydenalski, 1915.

Tucker, L. R., \& Messick, S. An individual differences model for multidimensional scaling. Psychometrika, 1963, 28, 333-367.

W Allach, H., \& Austin, P. A. Recognition and the localization of visual traces. American Journal of Psychology, 1954, 67, 338-340.

W ARD, J. H. Hierarchical grouping to optimize an objective function. American Statistical Association Journal, 1963, 58, 236-244.

(Received for publication February 19, 1976.) 